\title{
Parque Verde do Mondego: gestão e uso público
}

\author{
Mondego Green Park: public use and management
}

Yuli Della Volpi, Reinaldo Pacheco

Universidade de São Paulo (USP), Escola de Artes, Ciências e Humanidades (EACH), São Paulo, SP, Brasil

\section{Resumo}

0 presente artigo se refere a um estudo de caso que teve como recorte espacial o Parque Verde do Mondego, localizado às margens do Rio Mondego, na cidade de Coimbra, em Portugal. A pesquisa teve como objetivo compreender a gestão da área e o uso público do espaço. Para tanto, realizou-se, inicialmente, uma pesquisa bibliográfica e documental; em seguida, foram feitas diversas visitas ao parque e, por fim, uma entrevista com o responsável pela administração do local. Pôde-se, por meio do estudo, compreender o processo de criação do Parque Verde do Mondego, sua concessão para as empresas privadas, realizada por meio de concursos públicos, e seu uso pela população da cidade de Coimbra. Foram verificados ainda a carência de atividades de animação sociocultural na área - embora exista na cidade de Coimbra um curso de graduação em Animação Socioeducativa -, os conflitos existentes entre setor público e privado, além de determinados problemas que atingem atualmente o parque, como as inundações causadas pelas cheias do Rio Mondego.

Abstract

Palavras-chave: Parques urbanos. Uso público. Terceirização.

This research aims to understand the management and the public use of the Mondego Green Park, located on the Mondego River banks, in Coimbra, Portugal. Therefore, it was necessary to conduct bibliographical and documentary research, as well as several visits to the park and an interview with the current responsible for managing the area. It was possible to understand the creation process of the Green Park, its privatization process and its use by the population of Coimbra and note the lack of socio-cultural activities in this area, despite the existence of an undergraduate degree about this subject in the city, as well as conflicts between public and private sector and the problems faced nowadays.

Keywords: Urban parks. Public use. Privatization.

YDV é bacharel em Lazer e Turismo pela Escola de Artes, Ciências e Humanidades da Universidade de São Paulo (EACH-USP), e-mail: yuli.volpi@usp.br

RP é docente em Lazer e Turismo na Escola de Artes, Ciências e Humanidades da Universidade de São Paulo (EACH-USP), e-mail: repacheco@usp.br 


\section{Introdução}

Pode-se notar que, no decorrer da história, a relação entre o homem e o meio natural, marcada inicialmente por uma necessidade do ser humano em dominar a natureza, afastando-se das áreas naturais, mudou. Por meio da procura pelas praias, montanhas, ilhas, bosques e parques, o homem tem buscado uma reaproximação física e apresentado um conjunto de ideias que envolvem a natureza e a conservação do meio ambiente (Bahia, 2012).

Segundo Loboda \& De Angelis (2005), a história das áreas verdes urbanas começa com a jardinocultura, cujo surgimento se deu paralelamente e de forma independente no Egito e na China. Ainda segundo os autores, até o século XVIII, a tradição da jardinagem egípcia foi transmitida no Ocidente pelos persas, gregos, romanos, italianos, franceses e árabes, enquanto a China e os jardins naturalistas exerceram forte influência sobre os japoneses. Anteriormente, na Idade Média, destacavam-se outras formas de jardinaria, como os jardins árabes. 0 Renascimento trouxe a influência das arquiteturas para esses espaços, de forma que os jardins italianos permitiram a adaptação dessas áreas aos terrenos e os jardins franceses, por serem maiores em extensão, influenciaram o surgimento das praças e parques abertos à população.

Foi a Grécia, porém, o país pioneiro onde esses espaços passaram a assumir função pública, tornando-se lugares de lazer da população. De acordo com Loboda \& De Angelis (2005, p. 127), “[...] lá surgiu o conceito de espaço livre atribuído a Roma, onde um jardim privado, propriedade da nobreza é convertido em espaços livres para usufruto da comunidade".

Assim, os primeiros parques urbanos foram criados em paralelo à formação das cidades no século XVIII na Europa e também nos Estados Unidos da América, motivados pela urbanização e pela industrialização (Silva \& Pasqualetto, 2013).

Segundo Matos et al. (2005), no caso de Portugal, com a migração significativa da população rural para os centros urbanos, gerando o crescimento urbano, ocorreram mudanças nas políticas orientadas para as cidades. Assim, as ditas "cidades médias" - nas quais os aspectos qualitativos, dinâmicos e relacionais se sobrepõem ao demográfico - precisavam induzir a inovação e organizar os sistemas territoriais.

Fez-se necessário, nessas cidades, um maior planejamento urbano, inclusive com projetos de uso do solo e com a reordenação e formas de utilização dos espaços, levando em consideração as funções existentes na cidade. Assim, o primeiro jardim público de Portugal foi o "Passeio Público", construído no século XVIII. É importante ressaltar que as principais cidades portuguesas sempre contaram com hortos e jardins. Estes, no século XIX, deixaram uma marca de relevo positiva para a salubridade e higienização do espaço urbano, que foi reproduzida pelas recomendações dos congressos internacionais de urbanismo de Paris, em 1907, e pela Carta de Atenas, em 1933 (Matos et al., 2005).

Dessa forma, com o aumento no número dos jardins nas cidades portuguesas e com a valorização e o redimensionamento dos espaços verdes, além da construção de novas vias de acesso, como avenidas e alamedas que passaram a ligar os espaços abertos, criaram-se os parques verdes (Matos et al., 2005).

Como ressaltado por Figueiredo et al. (2013), as áreas verdes não devem ser confundidas com 'vazios espaciais'. Esses locais completam a dinâmica e participam do cotidiano das cidades como espaços em que se desenvolvem atividades de lazer, esporte e cultura - que incluem o descanso e a observação da paisagem, assim como práticas esportivas de baixo impacto - por moradores e turistas.

Para Tschoke et al. (2010), os espaços públicos representam locais em que são vivenciadas as diferenças e afinidades sociais. Segundo as autoras, eles apresentam diversas possibilidades de diálogo e transformação, sendo tanto lugar de conflito quanto de convivência.

Essa ideia é reforçada por Rechia \& Betrán (2010), que dizem que os espaços públicos de lazer das cidades são lugares de socialização, potencialização das identidades culturais e de possibilidades de relações multiculturais e integração social.

Além disso, as áreas verdes urbanas valorizam o ambiente e a estética, trazendo ótimas oportunidades para a realização de atividades de recreação e educação da comunidade, contribuindo também para a qualidade de vida nas cidades (Hildebrand et al., 2001).

Os parques urbanos são, portanto, áreas verdes de uso público e apresentam vantagens estéticas, ecológicas e sociais. São áreas voltadas ao paisagismo, à preservação ambiental e ao lazer da população (Loboda \& De Angelis, 2005). São também espaços propícios para a realização de atividades de animação. 
Como o próprio nome sugere, a animação sociocultural é formada pelas dimensões social, cultural e ainda educacional. A dimensão social refere-se à participação nos grupos e comunidades; a cultural encoraja a expressão criativa e a educacional é capaz de promover o desenvolvimento dos indivíduos por meio do envolvimento deles com as atividades (Foth, 2006).

Nesse sentido, a animação sociocultural pode ser entendida como um conjunto de atividades sociais e culturais que estimulam a participação e a iniciativa da população durante seu desenvolvimento e na dinâmica política e social em que se inserem (Lopes, 2006).

Pode-se dizer ainda que as atividades realizadas nesses espaços devem ser atividades de animação socioambiental, cujo conceito é novo e que surgiu com a proposta de atender às necessidades de lazer dos usuários de parques e demais áreas que envolvem a proteção do meio ambiente, tendo como objetivo a conservação dos elementos da natureza. Para tanto, a animação socioambiental deve despertar a compreensão e a sensibilização do usuário sobre as características naturais e culturais do local, educando-os para essas questões por meio dos interesses do lazer dos visitantes, unindo, assim, os conceitos de animação sociocultural e interpretação ambiental (Raimundo \& Pacheco, 2014).

\section{Aproximação com o Parque Verde do Mondego}

A cidade de Coimbra está localizada às margens do Rio Mondego, em Portugal. Esse rio é considerado o maior a ter todo o seu curso no país, com nascente na Serra da Estrela e foz no Oceano Atlântico, na cidade de Figueira da Foz. O Parque Verde do Mondego, objeto do presente artigo, foi inaugurado em junho de 2004, fazendo parte do plano estratégico de Coimbra (Programa Polis), que visava aproximar o rio e a vivência da cidade (Coimbra, 2014).

A inauguração do Parque Verde do Mondego proporcionou para a cidade de Coimbra uma requalificação urbana e também representou um ganho para os habitantes como um novo espaço de lazer. Nesse sentido, o objetivo do presente artigo foi compreender tanto a gestão quanto as diferentes funções e usos do parque, a partir da ampla gama de possibilidades oferecidas pelo espaço - atualmente, possui estabelecimentos, como restaurantes e bares.
Para tanto, o estudo baseia-se no método do estudo de caso, pois se foca em uma unidade - no caso, o Parque Verde do Mondego - e busca melhor compreender um caso particular (Ventura, 2007). Foi necessário, inicialmente, realizar uma pesquisa bibliográfica sobre os temas de parques urbanos e áreas de lazer e uma pesquisa documental sobre a implantação e gestão do Parque Verde do Mondego.

Durante a realização do levantamento bibliográfico, observou-se a carência de estudos que compreendessem o desenvolvimento, gestão e uso público dos parques urbanos de Portugal. Houve ainda dificuldade em encontrar informações acerca da história do Parque Verde do Mondego, embora se tenha verificado certo comprometimento, tanto por parte da Universidade de Coimbra quanto do Instituto Politécnico de Coimbra, em desenvolver trabalhos de graduação sobre o Parque Verde do Mondego.

Além disso, foi realizada uma entrevista semiestruturada com o atual responsável pela empresa que gerencia o parque, para se compreender melhor o processo de terceirização da área.

Por fim, foram realizadas diversas visitas ao espaço, com o objetivo de observar e coletar dados sobre o uso do Parque Verde pela população da cidade de Coimbra. Houve ainda o acompanhamento de um grupo de alunos do curso de Animação Socioeducativa da Escola Superior de Educação de Coimbra (ESEC), do Instituto Politécnico de Coimbra, durante a realização de uma atividade do curso no parque. Foi possível, na ocasião, manter conversas informais com a professora Lucília Salgado, docente do curso de Animação Socioeducativa, e coletar outras informações sobre o uso da área, antes e depois da criação do Parque Verde do Mondego.

Faz-se importante ressaltar que a relação entre o Rio Mondego e a cidade de Coimbra é marcada por inundações de sua planície aluvial. Os primeiros registros sobre as cheias do Mondego e das medidas tomadas para minimizar e controlar os impactos são de longa data. As populações ribeirinhas sofriam com o frequente extravasamento das águas do rio. Em 1962, foi desenvolvido o Plano Geral de Aproveitamento da Bacia do Mondego, no qual havia propostas para a construção de barragens e leitos marginados de diques que não pudessem ser transponíveis pelas águas. Logo, a possibilidade de cheias foi reduzida (Paiva, 2011). 
As barragens da Aguieira-Raiva e Açude-Pote, no Rio Mondego, e a das Fronhas, no Alva, eliminaram quase completamente as inundações na parte terminal da bacia. Porém ainda ocorrem cheias, com menor frequência, durante os períodos de inverno, quando as chuvas são mais críticas, a exemplo da séria inundação ocorrida em janeiro de 2001 (Paiva, 2011).

Como informado por Lucília Salgado, moradora de Coimbra e docente no curso de Animação Socioeducativa da ESEC, antes da construção do Parque Verde, a área que margeia o Rio Mondego era repleta de laranjeiras, não sendo utilizada pela população, salvo um pequeno número de pescadores que se colocava entre as laranjeiras, à beira do Mondego.

Estudos realizados por estudantes da Universidade de Coimbra, como é o caso daquele desenvolvido por Mano (2011), apontam que o rio foi um aspecto que condicionou o desenvolvimento demográfico da cidade devido às inundações e às vertentes abruptas que dificultaram a construção urbana. A criação de barragens e a plantação de árvores e arbustos perto do rio e em suas vertentes colaboraram para evitar o agravamento das cheias - posteriormente, foram realizadas intervenções na bacia hidrográfica do Mondego.

Dessa forma, pode-se perceber que, antes da criação do parque, a área do entorno do Parque Verde do Mondego não servia aos interesses do lazer da maior parte da população, estando voltada apenas para a prevenção de impactos negativos de possíveis inundações do rio.

Essa realidade, porém, começou a ser alterada em 1995, quando foi realizada a primeira fase de um concurso público para o projeto de execução do Parque Verde do Mondego, posteriormente incluído no Programa Polis de Coimbra. A criação do parque visava possibilitar o usufruto desse espaço pela população, a partir da qualificação das margens do Rio Mondego (Coimbra, 1995).

O Parque Verde do Mondego foi então construído às margens do Rio Mondego, projetado pelo arquiteto Camilo Cortesão e inaugurado em junho de 2004 (Coimbra, 2014).

De acordo com Coimbra (2014), a área do parque localizada na margem direita do Rio Mondego possui mais de $400 \mathrm{mil} \mathrm{m}^{2}$ e é dedicada ao lazer.

Esse espaço conta com ampla zona de esplanadas e corredores para caminhada e ciclismo, bar, restaurante, além de diversos pavilhões de exposições temporárias
- incluindo o Pavilhão Centro de Portugal (Pavilhão de Portugal construído para a Expo 2000, de Hannover), utilizado por uma orquestra (Orquestra Clássica do Centro, 2014).

A ponte pedonal "Pedro e Inês", inaugurada em novembro de 2006, apresenta vidros de cores diferentes ao longo das grades de proteção e possui $275 \mathrm{~m}$ de comprimento por $4 \mathrm{~m}$ de largura. Ela foi projetada pelos engenheiros Adão da Fonseca e Cecil Balmond - sendo também parte do Programa Polis -, conectando a margem direita à margem esquerda do rio (Turismo de Coimbra, 2014).

A margem esquerda, por sua vez, possui equipamentos de diversão infantil, um parque de skate, um parque de merendas, caixa de areia para prática de voleibol e quatro pavilhões - três deles abrigando clubes de atividades náuticas, como a canoagem, remo e a vela - além de piscinas descobertas, bar e restaurante (Coimbra, 2014).

\section{O Programa Polis}

O Programa Polis Cidades, aprovado pela Resolução do Conselho de Ministros no 26/2000, visa à requalificação urbana e à valorização ambiental de cidades portuguesas, procurando disseminar no país a experiência organizacional e urbanística desenvolvida na Expo 98 (Exposição Internacional de Lisboa de 1998), que permitiu o estabelecimento de um novo modelo de valorização e proteção ambiental e de qualidade urbana (Portugal, 2000).

Para tanto, o Programa é institucionalmente consolidado em sociedades gestoras locais, que são como sociedades anônimas de capital público, formadas a partir de parceria entre o Estado e os municípios e às quais cabe a execução de planos estratégicos aprovados. Acredita-se que, dessa forma, as ações podem ser promovidas garantindo a qualidade e a coerência dos projetos e obras, a partir de recursos financeiros gerados, em grande parte, por meio de programas comunitários de apoio existentes.

O Programa Polis tem iniciativas que visam melhorar a qualidade de vida em diferentes cidades e que compreendem quatro desígnios estratégicos, a saber: Cidades Verdes, Cidades Digitais, Cidades do Conhecimento e do Entretenimento e Cidades Intergeracionais (Portugal, 2000). 
Pode-se concluir que Coimbra esteve enquadrada no desígnio "Cidades Verdes", já que o objetivo de centrar a cidade no rio atribuiu ao ambiente um papel importante para a requalificação urbana, por criar um espaço público de qualidade e valorizar uma característica do meio ambiente, assim como foi proposto pela Resolução do Conselho de Ministros de 2000 para as iniciativas voltadas para as "Cidades Verdes".

Assim, com relação à cidade de Coimbra, o Programa Polis perseguiu o objetivo de revitalizar a cidade, centrando-a em um elemento ambiental possível de ser valorizado, o Rio Mondego.

\section{A administração do Parque Verde do Mondego}

Ambas as margens do Rio Mondego possuem estabelecimentos que foram, também por meio de concurso público, concedidas para a exploração de empresas privadas. Em um dos lados do parque, na margem esquerda, a piscina descoberta, o bar e o restaurante foram cedidos por intermédio de concurso público, entrando em funcionamento no ano de 2010.

0 concurso público foi realizado por um Caderno de Encargos, em 2009, que definia a área, os equipamentos e os detalhes dos edifícios, além das obrigações do concessionário com relação às diferentes áreas esplanadas, espaço verde interior e piscinas - que incluíam desde a montagem e fornecimento dos equipamentos do bar e do balcão de atendimento, equipamento para a sala de primeiros socorros e do escritório, até pormenores, como o tipo de material permitido para as mesas das esplanadas, proibição da colocação de tapetes e esteiras, restrições quanto aos equipamentos, período de funcionamento das piscinas etc. (Coimbra, 2009). Os estabelecimentos de alimentação e afins da margem oposta do rio também tiveram a licença atribuída por meio do concurso público.

Em entrevista realizada com o proprietário da empresa "Complexo Verde do Mondego", que obteve a licença de atuação na margem direita, tornando-se responsável pela área e por dois bares, um restaurante e uma sorveteria, notou-se a insatisfação do agente privado com a administração pública. 0 senhor Antônio Silva diz sentir falta do apoio dos Postos de Turismo e da Câmara Municipal, que parecem deixar toda a responsabilidade da gestão do parque para as empresas privadas.

No início de 2014 devido a uma nova inundação do Rio Mondego, o parque e os estabelecimentos ficaram alagados (Figura 1). De acordo com Antônio, o problema é causado pela falta de desassoreamento do rio, pelo qual a Câmara não quer se responsabilizar. Dessa forma, com as cheias que afetaram os estabelecimentos, o proprietário está em busca de um seguro. Segundo ele, os seguros em Portugal não fazem cobertura das estruturas e das áreas externas.

Ao buscar por informações com relação ao Parque Verde na Câmara Municipal de Coimbra, o desinteresse relatado pelo agente privado pôde ser verificado. Segundo as informações prestadas pelo atendente, a manutenção do parque e os estabelecimentos ali presentes são de responsabilidade das empresas, pois para a Câmara Municipal se torna mais confortável.

Foi possível notar ainda a falta de informação disponibilizada acerca do Parque Verde do Mondego pelo Posto de Turismo, cuja localização está a aproximadamente $1 \mathrm{~km}$ dali. Embora exista a indicação do Parque Verde como atrativo, não são disponibilizadas informações mais detalhadas sobre a história e importância do local.

A estrutura geral visível do parque é aparentemente muito boa. Novamente segundo Antônio, os serviços de manutenção e segurança do Parque Verde são de sua responsabilidade, mas que, por sua vez, contrata outra empresa para realizá-los.

0 parque encontra-se conservado e limpo, com a grama aparada e as árvores podadas, embora durante uma observação mais detalhada possam ser notados alguns problemas, como algumas partes do chão que foram afetadas pela água da chuva, latas de lixo que se encontram desgastadas e alguns vidros trincados na ponte que leva ao outro lado do rio (Figura 2). Outro aspecto que pode ser verificado diz respeito às pichações realizadas na ponte, que podem representar uma forma de expressão de um determinado grupo que utiliza a área do parque. Essas formas de expressão podem se tornar objeto de projetos específicos de animação socioambiental (Figura 3).

Além disso, um dos principais pontos de referência encontrados no parque - o grande urso de relva localizado às margens do Mondego - já foi vítima de vandalismo. 0 urso original, construído em relva natural, colocado no Parque Verde após ter sido utilizado em uma exposição promovida pelo Museu da Ciência e 


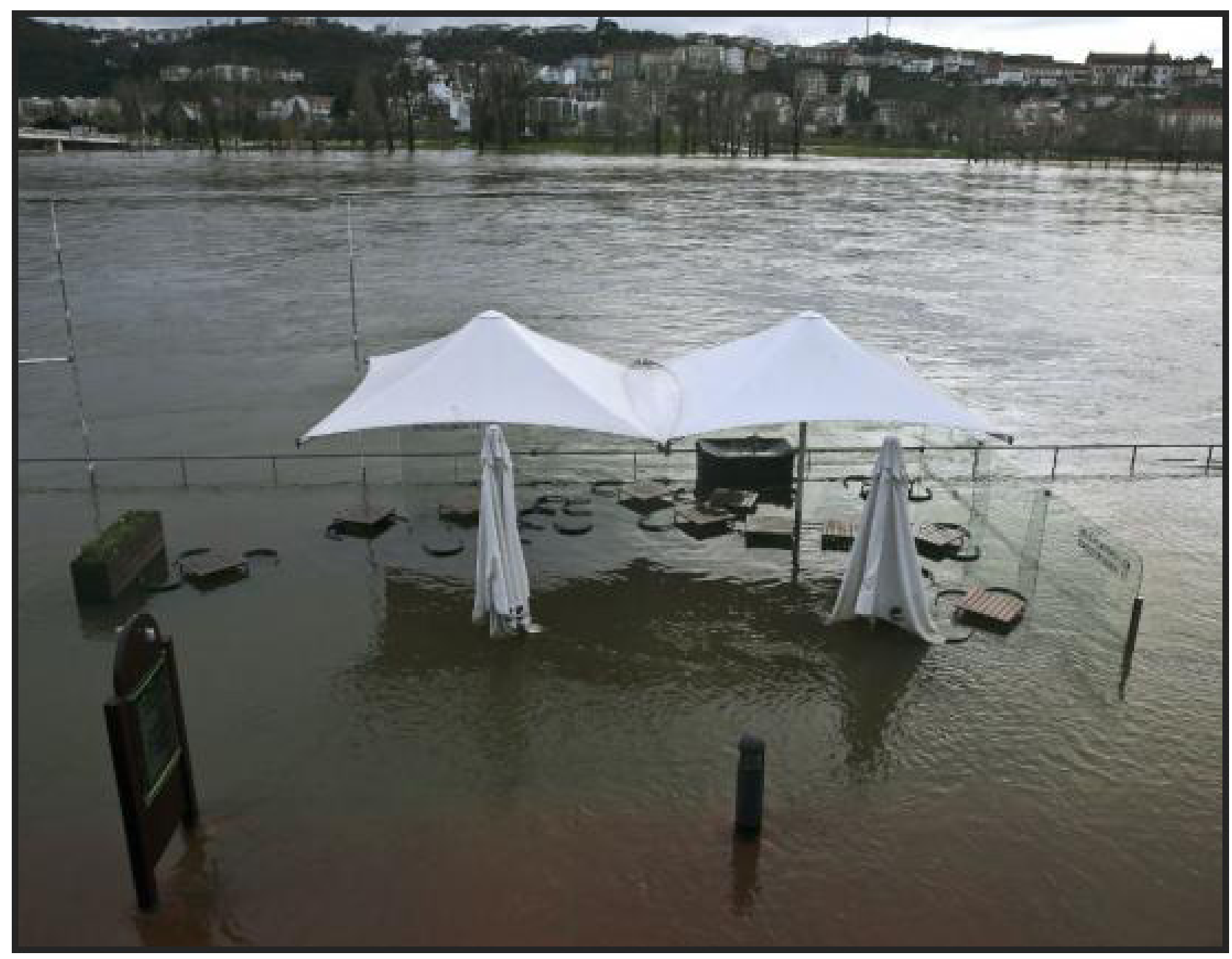

Figura 1 - Alagamento do Parque Verde do Mondego Fonte: Tvi24 (2014).

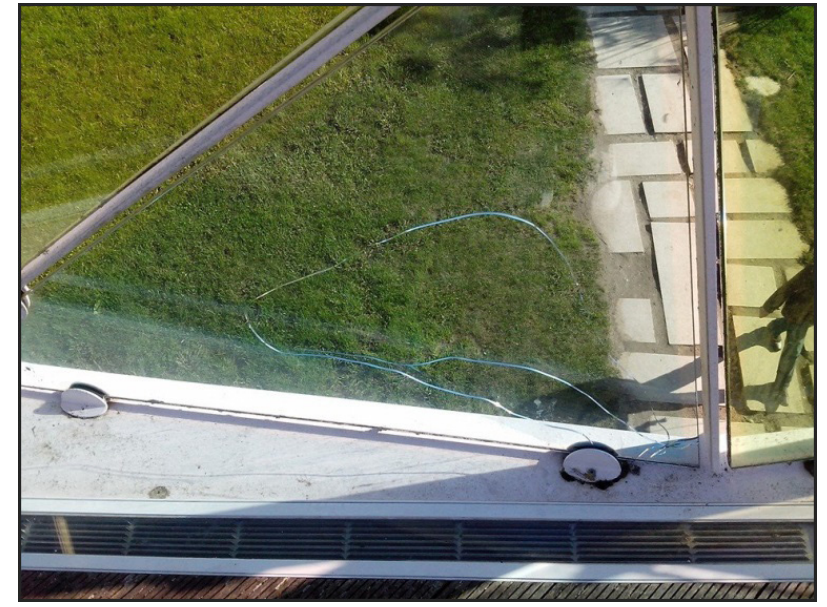

Figura 2 - Vidro trincado da ponte do Parque Verde do Mondego Foto: Elaborado pelos autores.

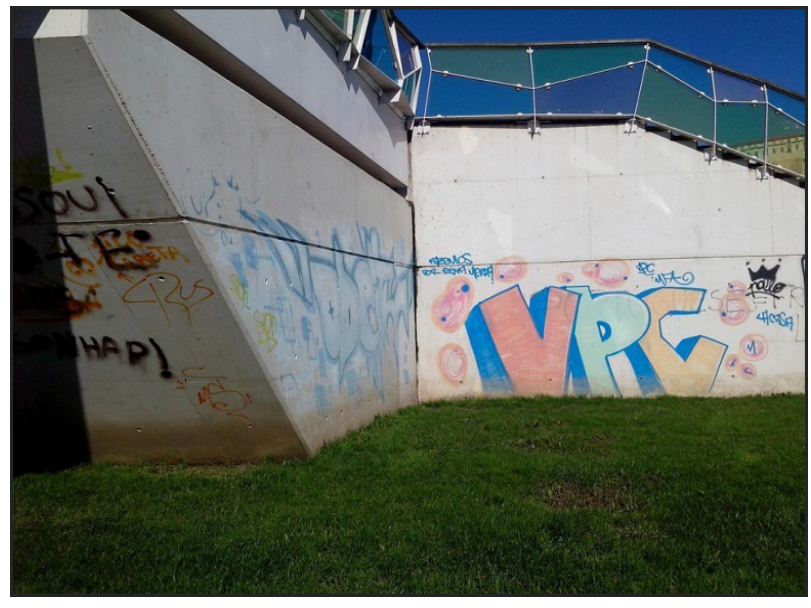

Figura 3 - Pichação na ponte "Pedro e Inês", do Parque Verde do Mondego Foto: Elaborado pelos autores. 
da Técnica, foi queimado em um incêndio criminoso em 2005 (Campos, 2005). Segundo o concessionário Antônio Silva, sua restauração, que consistiu na construção de um novo urso utilizando-se de outro material, ficou sob sua responsabilidade. 0 novo urso, entretanto, já se encontra danificado (Figura 4).

Logo, pode-se perceber um conflito de interesses entre setor público e privado que resulta em problemas para o funcionamento do Parque Verde do Mondego e, consequentemente, para os usuários do parque.

\section{Utilização do Parque Verde do Mondego pela população}

A função e a configuração dos parques urbanos se diferenciam de acordo com a gestão ambiental e os padrões de crescimento das cidades. Por esse motivo, alguns parques são estruturados a fim de atender à maior quantidade de pessoas, enquanto outros estão voltados para a conservação ambiental. Apesar dessas diferenças, todas essas áreas tendem a colaborar para a qualidade de vida da população dos núcleos urbanos (Cardoso et al., 2015). Segundo Takano et al. (2002), os espaços verdes, assim como a presença de locais adequados para a caminhada, ruas tranquilas e arborizadas, são capazes de influenciar positivamente a longevidade dos cidadãos.

O Parque Verde do Mondego foi estruturado para o uso público e, atualmente, atende à Seção de Desportos Náuticos da Associação Acadêmica de Coimbra, o Clube Fluvial de Coimbra, o Clube do Mar

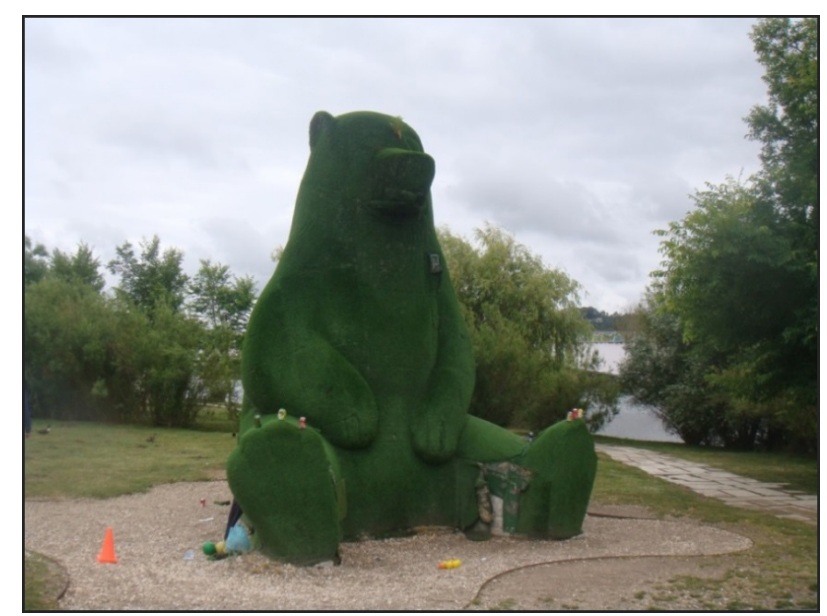

Figura 4 - Urso de relva artificial nas margens do Rio Mondego Foto: Elaborado pelos autores. de Coimbra e a Faculdade de Ciências do Desporto e Educação Física da Universidade de Coimbra, além do público geral, que utiliza o parque para atividades de lazer (Coimbra, 2014).

Com relação aos eventos realizados, em 2013 ocorreu a feira do livro e, durante o primeiro semestre de 2014, houve a corrida de $5 \mathrm{~km}$ chamada "The Color Run" (Figura 5), que reuniu pessoas de todas as idades na área do parque.

Durante as visitas ao parque, pôde-se constatar que, em geral, os pequenos pavilhões de exposições espalhados pela área encontravam-se sempre fechados e que grupos de estudantes e instrutores de diferentes atividades físicas costumam realizar algumas atividades ali.

Foi possível acompanhar ainda uma das atividades realizadas por estudantes do segundo ano do curso de Animação Socioeducativa da ESEC, em maio de 2014.

Esse curso visa formar profissionais capazes de atuar na criação, gestão e direção de instituições e projetos, além de formar animadores e coordenadores de equipes que trabalhem com projetos educativos $\mathrm{e}$ pedagógicos no contexto da formação, aprendizagem, desenvolvimento local e lazer (ESEC, 2008).

Os estudantes aproveitaram as diversas áreas do parque para desenvolver diferentes atividades de animação, todas de caráter lúdico e educativo. Um dos objetivos propostos pela docente Lucília Salgado foi fazer com que os estudantes conhecessem melhor o Parque Verde e suas possibilidades de uso para a elaboração de atividades de animação socioeducativa.

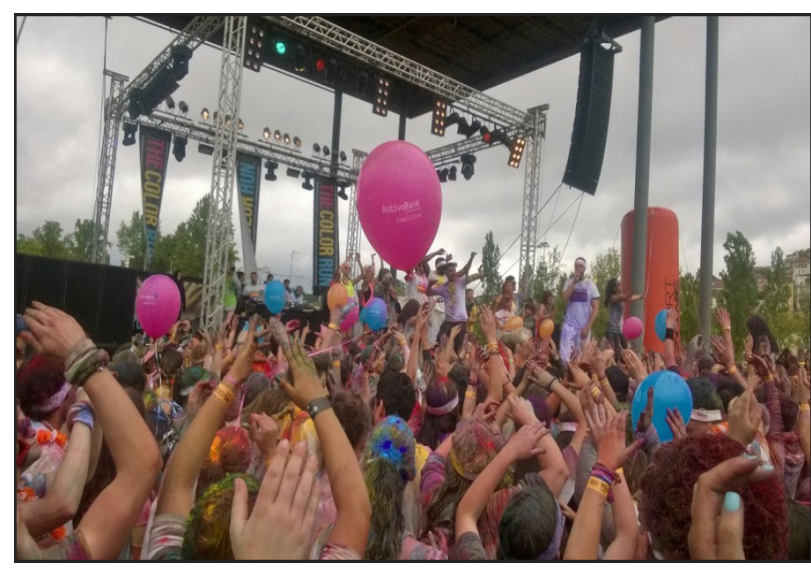

Figura 5 - Final da "The Color Run", no Parque Verde do Mondego, com comemoração e apresentações musicais Foto: Fillipe Romano (arquivo pessoal). 
Dessa forma, os estudantes deveriam desenvolver, em grupos, atividades de animação que satisfizessem cinco diferentes objetivos, dentre eles o que foi chamado de "objetivos de saber". Para cumpri-lo, os alunos deveriam fazer com que, por meio de atividades, os participantes obtivessem mais informações e conhecessem melhor o parque.

Pode-se citar como exemplo de algumas das atividades realizadas que permitiram que o objetivo fosse alcançado: perguntas acerca da história do Parque Verde, mesclado com atividades esportivas; quebra-cabeça a ser montado com peças que os participantes ganhariam quando cumprissem bem alguma outra atividade, contendo, de um lado, uma palavra relacionada ao parque e, do outro, parte de uma imagem de referência do local, como o grande urso de relva artificial colocado próximo à margem do Rio Mondego; a utilização de um pequeno mapa que permitia que os estudantes conhecessem melhor a área em que estavam etc. (Figuras 6 e 7).

Após a realização das atividades, alguns dos estudantes relataram o desejo de voltar a desenvolver práticas de animação no parque, pois era um espaço bastante propício. Essa é uma necessidade verificada durante as visitas, já que atividades de animação sociocultural não costumam ser realizadas na área, com exceção daquelas desenvolvidas por alunos no âmbito de alguma disciplina.

Por fim, foi possível observar, com frequência, pessoas de todas as idades utilizando o espaço do Parque Verde do Mondego como área de descanso, relaxamento, levando seus animais de estimação para passear ou praticando diferentes modalidades esportivas (Figuras 8, 9 e 10).

Embora haja grande diversidade entre os usuários, o parque comporta bem a quantidade de pessoas que costuma utilizá-lo, não aparentando estar lotado em nenhum horário do dia.

Logo, verifica-se que o parque possui estrutura para a execução de diferentes atividades de animação, além de potencial para a realização de grandes eventos, embora essa capacidade pareça não estar sendo aproveitada ao máximo.

Contudo, é importante ressaltar que a área atende a diversos usuários e representa um importante espaço de lazer para os moradores de Coimbra.

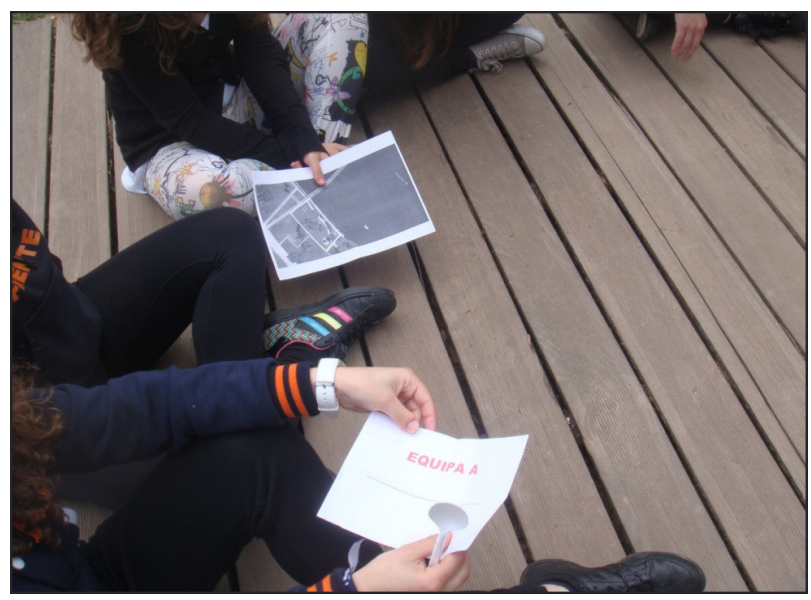

Figura 6 - Divisão das equipes e distribuicão do mapa do Parque Verde durante uma das atividades de animação realizada pelos alunos da ESEC no Parque Fonte: Elaborado pelos autores.

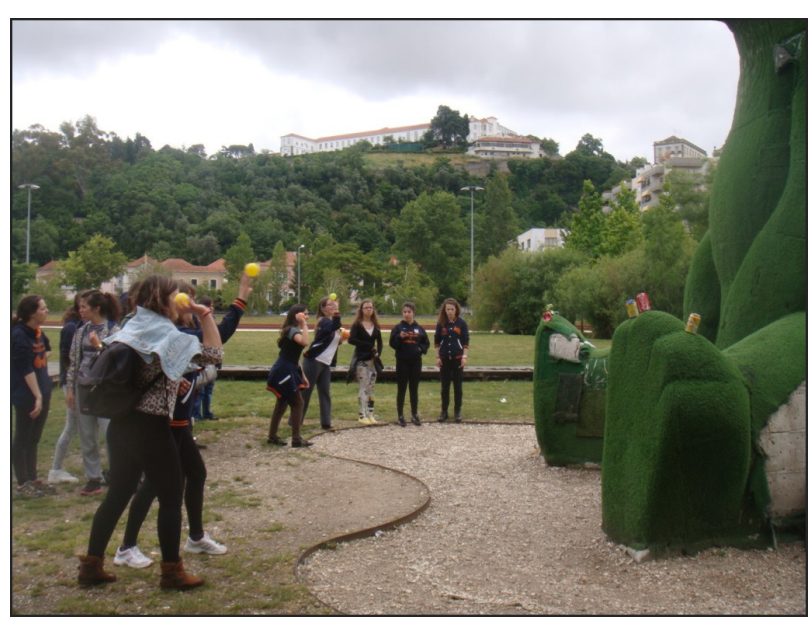

Figura 7 - Estudantes da ESEC desenvolvendo atividades de animaç̃õo socioeducativa no Parque Verde do Mondego Foto: Elaborado pelos autores.

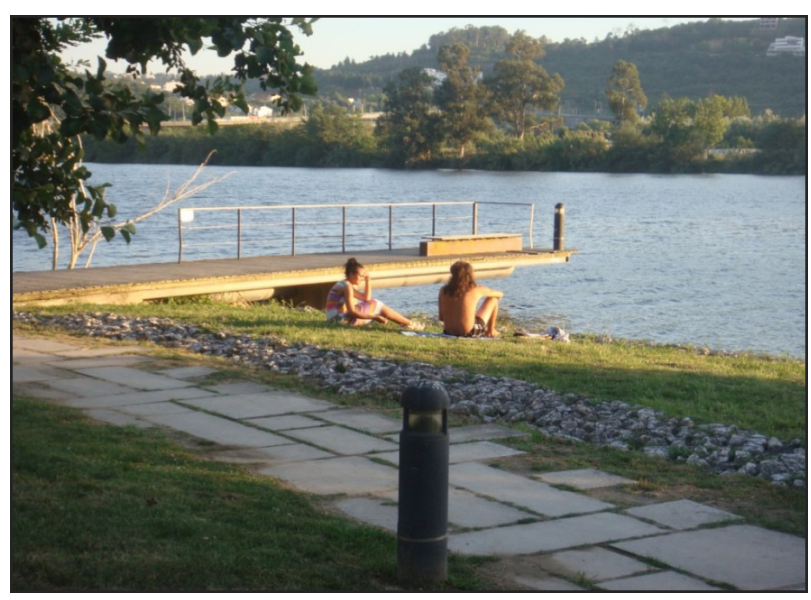

Figura 8 - Casal descansando e apreciando a paisagem no Parque Verde, às margens do Rio Mondego

Foto: Elaborado pelos autores. 


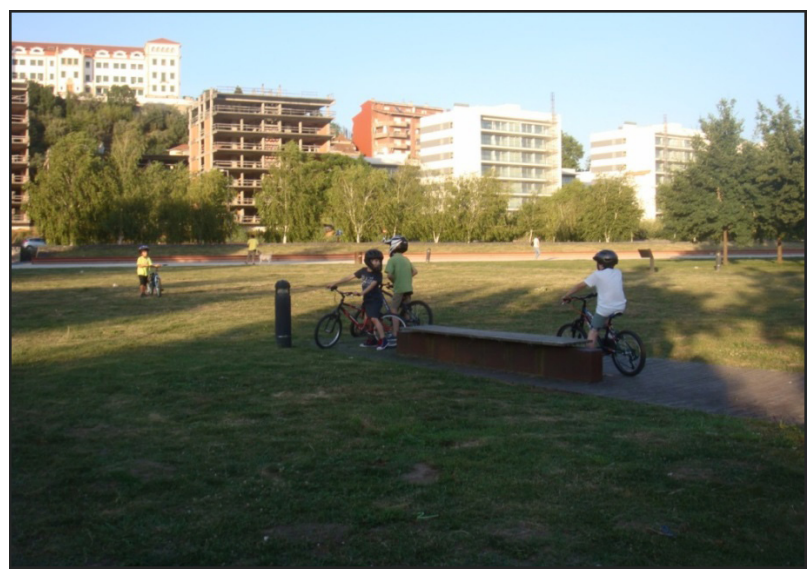

Figura 9 - Crianças brincando no Parque Verde do Mondego. Nota-se ainda, ao fundo, novos projetos imobiliários que foram desenvolvidos com a implantação do parque

Foto: Elaborado pelos autores.

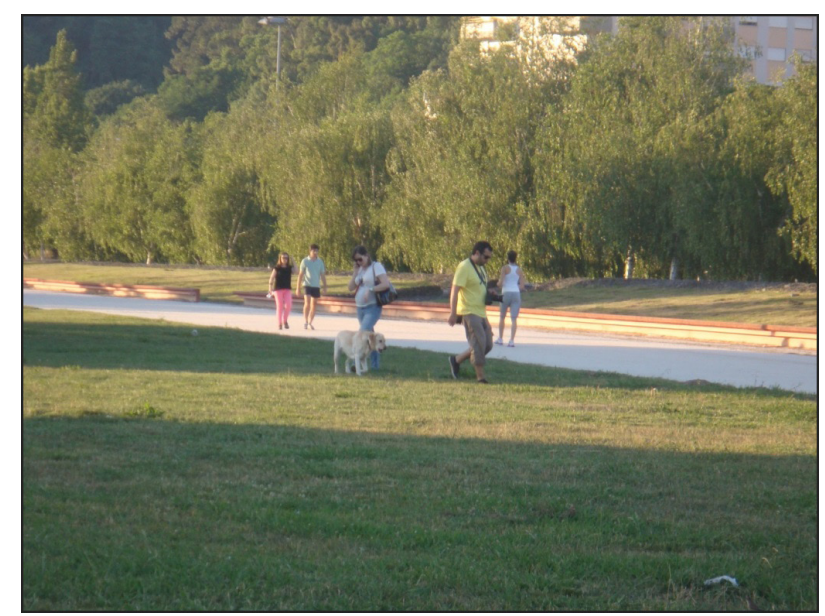

Figura 10 - Usuário do Parque Verde e seu animal de estimação Foto: Elaborado pelos autores.

\section{Considerações finais}

Pôde-se, por meio da pesquisa, compreender a relação entre o Parque Verde do Mondego e a cidade de Coimbra.

O espaço do parque, temporariamente concedido a empresas, tem estado sob responsabilidade privada. Sendo assim, constamos que há conflitos entre os setores público e privado para a manutenção de determinados aspectos - como a necessidade de desassoreamento do Rio Mondego - que afetam tanto os estabelecimentos localizados no parque quanto os usuários das áreas públicas.
Há, portanto, uma necessidade de maior diálogo entre esses setores, no sentido de resolver os conflitos e evitar maiores problemas como aqueles causados pela inundação do Parque Verde.

Embora existam problemas, a concessão do espaço para as empresas privadas se mostrou eficiente, pois a área do parque apresenta-se, de modo geral, conservada e recebe usuários de todas as idades.

Porém, constata-se que, embora ocasionalmente existam eventos realizados nas dependências do Parque Verde, a exemplo da "The Color Run", o parque não possui ações de animação socioambiental. Esse dado é um tanto quanto surpreendente ao levar-se em consideração que, na ESEC, existe o curso de Animação Socioeducativa. Pode-se, nesse sentido, apontar novamente certo descaso do poder público, que poderia incentivar a realização de atividades de animação na área do Parque Verde do Mondego mediante, por exemplo, a contratação de funcionários que planejassem e executassem atividades culturais e educativas com frequência.

Sendo assim, os usuários parecem usufruir do espaço especialmente para o descanso e atividades esportivas. 0 parque, porém, possui estrutura para a realização de diversas atividades, havendo, inclusive, pavilhões na área que, infelizmente, não são devidamente utilizados - durante todas as visitas realizadas ao parque, estavam fechados -, o que não contribui para a utilização de todo o potencial do espaço. Verifica-se, portanto, a possibilidade de um melhor aproveitamento da área no que tange à realização de eventos e atividades de animação socioambiental, de modo que o Parque Verde do Mondego se torne, cada vez mais, um espaço público que reúna diversas opções de lazer a fim de atender a diferentes interesses da população.

\section{Referências}

Bahia, M. C. (2012). O lazer e as relações socioambientais em Belém-Pará (Tese de doutorado). Universidade Federal do Pará, Belém.

Campos, J. L. (2005). Urso de relva destruído em incêndio criminoso. Porto: Jornal de Notícias. Recuperado em 20 de julho de 2014, de http://www.jn.pt/paginainicial/interior. aspx?content_id=527674 
Cardoso, S. L. C., Vasconcellos, M. V., So., \& Vasconcellos, A. M. A. (2015). Gestão ambiental de parques urbanos: o caso do Parque Ecológico do Município de Belém Gunnar Vingren. urbe. urbe. Revista Brasileira de Gestão Urbana, 7(1), 7490. http://dx.doi.org/10.1590/2175-3369.007.001.A005.

Coimbra. Câmara Municipal de Coimbra. (1995). Acta da Reunião da Câmara Municipal de Coimbra realizada no dia trinta e um de julho de mil novecentos e noventa e cinco. Coimbra: Câmara Municial de Coimbra. Recuperado em 21 de julho de 2014, de http://www.cm-coimbra.pt/ dmdocuments/ACTA950731.pdf

Coimbra. Câmara Municipal de Coimbra. (2009). Concurso público: Concessão da exploração das piscinas descobertas, do bar e do restaurante (Margem Esquerda do Mondego). Caderno de Encargos - Condições Técnicas. Coimbra: Câmara Municial de Coimbra.

Coimbra. Câmara Municipal de Coimbra. (2014). Parque Verde do Mondego. Coimbra: Câmara Municipal de Coimbra. Recuperado em 10 de dezembro de 2014, de https://www. cm-coimbra.pt/index.php?option=com_content\&task=vie $\mathrm{w} \& \mathrm{id}=820 \&$ Itemid $=350$

Escola Superior de Educação de Coimbra - ESEC. (2008). Licenciatura em Animação Socioeducativa. Coimbra: ESEC. Recuperado em 10 de fevereiro de 2015, de http://www. esec.pt/pagina.php?id=45

Figueiredo, S. L, Bahia, M. C., Cabral, P. T. M., Nóbrega, W. R. M., \& Tavares, A. E. P. (2013). Lazer, esporte e turismo: importância e uso das áreas verdes urbanas em Belém/ Brasil. LICERE - Revista do Programa de Pós-graduação Interdisciplinar em Estudos do Lazer, 16(1), 30-45.

Foth, M. (2006). Sociocultural animation. In S. Marshall, W. Taylor, \& X. Yu (Eds.). Encyclopedia of developing regional communities with information and communication technology (p. 640-645). Londres: Idea Group Reference. http://dx.doi. org/10.4018/978-1-59140-575-7.ch114

Hildebrand, E., Graça, L. R., \& Milano, M. S. (2001). Distância de deslocamento dos visitantes dos parques urbanos em Curitiba-PR. Floresta e Ambiente, 8(1), 76-83.

Loboda, C. R., \& De Angelis, B. L. D. (2005). Áreas verdes públicas urbanas: conceitos, usos e funções. Ambiência, 1(1), 125-139.

Lopes, M. S. (2006). Animação sociocultural em Portugal. Amarante: Intervenção.
Mano, A. (2011). A expansão da cidade de Coimbra ao longo do Rio Mondego. Coimbra: Universidade de Coimbra. Recuperado em 21 de fevereiro de 2015, de http://www4. fe.uc.pt/fontes/trabalhos/2011006.pdf

Matos, F., Lopes, J. C., \& Vitorino, M. A. (2005). Parque urbano e estratégias de bem-estar nas cidades médias em Portugal continental: 0 caso de Penafiel. In X Colóquio Ibérico de Geografia (p. 1-9). Évora: Universidade de Évora. Recuperado em 15 de fevereiro de 2015, de http://www. apgeo.pt/files/docs/CD_X_Coloquio_Iberico_Geografia/ pdfs/063.pdf

Orquestra Clássica do Centro. (2014). Pavilhão.Coimbra: Orquestra Clássica do Centro. Recuperado em 23 de agosto de 2014, de http://www.orquestraclassicadocentro.org/ pt-pt/pavilh\%C3\%A3o.aspx

Paiva, I. M. R. (2011). A Educação Ambiental no contexto da investigação em Hidrologia: as cheias do Mondego e as inundações urbanas em Coimbra enquanto caso de estudo. Colecção Iberografias, 17, 259-278.

Portugal. Presidência do Conselho de Ministros. (2000, 14 de abril). Resolução do Conselho de Ministros n. ${ }^{2} 26 / 2000$ de 15 de Maio. Lisboa: Diário da República. Recuperado em 28 de março de 2015, de http://siddamb.apambiente.pt/ publico/documentoPublico.asp?documento=22507\&versao=1

Raimundo, S., \& Pacheco, R. (2014). Parques Naturais do sul da Região Metropolitana de São Paulo (RMSP): os desafios para uma animação socioambiental. In J. D. L. Pereira, M. S. Lopes, \& M. A. Maltez (Eds.). Animação sociocultural: turismo, patrimônio, cultura e desenvolvimento local (p. 123-132). Chaves: Intervenção.

Rechia, S., \& Betrán, J. O. (2010). Parques urbanos de Barcelona: relação entre usos principais e combinados, a diversidade nas formas de apropriação e a segurança. Movimento, 16(3), 181-202.

Silva, J. B., \& Pasqualetto, A. (2013). 0 caminho dos parques urbanos brasileiros: da origem ao século XXI. Estudos, 40, 287-298.

Takano, T., Nakamura, K., \& Watanabe, M. (2002). Urban residential environments and senior citizens' longevity in megacity areas: the importance of walkable green spaces. Journal of Epidemiology and Community Health, 56(12), 913-918. http://dx.doi.org/10.1136/jech.56.12.913. PMid:12461111.

Tschoke, A., Maranho, M., \& Rechia, S. (2010). Espaço público de esporte e lazer: o espaço do (des) encontro 
da comunidade. In Anais do V Congresso Sul Brasileiro de Ciências do Esporte (p. 1-9). Itajaí: UNIVALI.

Turismo de Coimbra. (2014). Ponte Pedro e Inês. Coimbra: Câmara Municipal de Coimbra. Recuperado em 25 de junho de 2014, de http://turismodecoimbra.pt/company/ ponte-pedro-e-ines/

Tvi24. (2014). Mau tempo: situação do Parque de Coimbra é dramática. Coimbra: Tvi24. Recuperado em 02 de junho de 2014, de http://www.tvi24.iol.pt/503/sociedade/ coimbra-mau-tempo-parque-verde-despedimentos-chuvaparque-da-cidade/1536185-4071.html

Ventura, M. M. (2007). 0 estudo de caso como modalidade de pesquisa. Revista da SOCERJ, 20(5), 383-386.

Recebido: Maio 03, 2015

Aprovado: Jul. 10, 2015 